\title{
AVALIAÇÃO DA CINÉTICA DE CRESCIMENTO DA CIANOBACTÉRIA APHANOTHECE MICROSCOPICA NÄGELI NO EFLUENTE DE LATICÍNIO
}

\author{
J. G. VIEIRA ${ }^{1}$, N. M. STREIT ${ }^{1}$, A. G. DA S. MANETTI ${ }^{2}$, E. JACOB-LOPES ${ }^{3}$, M. I. \\ QUEIROZ $^{1}$ \\ ${ }^{1}$ Universidade Federal de Rio Grande, Escola de Química e Alimentos \\ ${ }^{2}$ Universidade Federal de Pelotas, Centro de Engenharias \\ ${ }^{3}$ Universidade Federal de Santa Maria, Departamento de Tecnologia e Ciência de \\ Alimentos \\ E-mail para contato: biotecnofurg@yahoo.com.br
}

RESUMO - O trabalho teve por objetivo avaliar a cinética de crescimento da Aphanothece no efluente de laticínio e sua capacidade de remoção de fósforo. Os cultivos foram conduzidos heterotroficamente utilizando o efluente de laticínios como meio de cultura em biorreatores. Realizou-se um planejamento experimental fatorial $\left(3^{2}\right)$, com os fatores: temperatura de cultivo $\left(10,20\right.$, e $\left.30^{\circ} \mathrm{C}\right)$ e concentração de inóculo (100; 200; 300 mg. $\left.\mathrm{L}^{-1}\right)$, pH 7,6, e tempo de detenção hidráulico de 24 h, C/N 20 e N/P 10. Considerou-se como resposta a remoção de fósforo e o crescimento celular. As variáveis dependentes foram monitoradas a cada $4 \mathrm{~h}$ durante as fases de crescimento. Os resultados indicaram 95,5\% de remoção de $\mathrm{P}_{-} \mathrm{PO}_{4}{ }^{-3}$ em até $24 \mathrm{~h}$ de cultivo no efluente de laticínio para a temperatura de $20^{\circ} \mathrm{C}$. Observa-se que a esta temperatura obteve-se os melhores valores cinéticos, resultando em máxima concentração celular de 0,84 g.L $\mathrm{L}^{-1}$, velocidade máxima de crescimento de $0,36 \mathrm{~h}^{-1}$ e produtividade de $160,25 \mathrm{~g} \cdot \mathrm{L}^{-1} \cdot \mathrm{dia}^{-1}$.

\section{INTRODUÇÃO}

Os resíduos de laticínios distinguem-se pela elevada carga de matéria orgânica, altos níveis de sólidos dissolvidos ou suspensos, óleos e gorduras, nutrientes tais como a amônia ou sais minerais e fosfatos e, portanto, requerem uma atenção adequada antes de sua eliminação (Sarkar et al., 2006).

$\mathrm{Na}$ maioria dos casos, esses efluentes não são tratados com o objetivo de remover nutrientes, visto que os tratamentos convencionais eliminam apenas matéria carbonada, contribuindo assim com elevadas concentrações de fósforo e compostos nitrogenados (Chimenos et al., 2006; Irdemez et al., 2006; Golder et al., 2006) acelerando o processo de eutrofização em seus corpos receptores.

O tratamento de efluentes lácteos é, portanto, um fator determinante não só para o ambiente, como também para fins de reciclagem de água para uso em processos industriais (Hamdani et al., 2005) visando redução de custos na planta de operação.

Neste contexto estão inseridos os sistemas de tratamento com microalgas. As características metabólicas destes organismos possibilitam a exploração de variados processos biotecnológicos, uma vez que podem crescer sob condições fotossintéticas, 
respiratórias e fixando nitrogênio atmosférico. Estas rotas metabólicas são passiveis de exploração tecnológica para tratamento de efluentes e produção de insumos.

O efeito da variação da concentração de inóculo e temperatura de cultivos têm sido muito estudados, uma vez que estes fatores atuam diretamente em quase todas as fases do metabolismo, particularmente nas reações de transformação de biocompostos e taxa de crescimento (Hafting, 1999; Shu \& Lung, 2003; Lee et al., 2007; Mishra \& Jha, 2009; Satpute et al., 2010).

A temperatura é um dos fatores determinantes para a composição da espécie microbiana (Fontenot et al., 2007) bem como da variação de sua atividade metabólica Além disso, desempenha uma importante função no controle da eutrofização de corpos hídricos minimizando a ação antrópica (Li et al., 2009). Em face disto o trabalho teve por objetivo avaliar a cinética de crescimento da Aphanothece no efluente de laticínio e sua capacidade de remoção de fósforo.

\section{MATERIAL E MÉTODOS}

\subsection{Micro-organismo}

Uma monocultura de Aphanothece microscopica Nägeli (RSMan92), originalmente isolada da Laguna dos Patos, no estado do Rio Grande do Sul, Brasil $\left(32^{\circ} 01^{\prime} \mathrm{S}-52^{\circ} 05^{\prime} \mathrm{W}\right)$ foi utilizada. As culturas foram propagadas e mantidas a $25^{\circ} \mathrm{C}$, intensidade luminosa de $15 \mu \mathrm{mol} . \mathrm{m}^{-2} . \mathrm{s}^{-1}$ (medida em luxímetro digital (Minipa MLM 1010) e fotoperíodo de $12 \mathrm{~h}$ na fase exponencial para tomada do inóculo. A concentração celular foi determinada por gravimetria, mediante filtração de volume conhecido de meio de cultura BG11 (Ripka et al., 1979), contendo células do microorganismo. Foram utilizados filtro Millipore de porosidade $0,45 \mu \mathrm{m}$ previamente seco a $60^{\circ} \mathrm{C}$ por $24 \mathrm{~h}$ (Queiroz et al., 2004).

\subsection{Meio de cultivo}

Os experimentos foram realizados em reator do tipo coluna de bolhas, construído em PVC de $4 \mathrm{~mm}$ de espessura, diâmetro interno de $10 \mathrm{~cm}$, altura de $100 \mathrm{~cm}$ e 4,5 L de volume de trabalho. $\mathrm{O}$ sistema de dispersão de gases do reator consistiu em um difusor de ar de 1,5 cm localizado no centro da base da coluna.

O meio de cultivo consistiu na água residuária do processamento de laticínios, no qual as amostras foram coletadas no tanque de equalização do sistema de tratamento de efluente de uma indústria localizada em Pelotas, RS, transportado para o Laboratório de Biotecnologia (FURG) em recipientes de polietileno e estocado a $4{ }^{\circ} \mathrm{C}$. A cada experimento o efluente foi descongelado e esterilizados a $1,1 \mathrm{kgf} \mathrm{cm}^{-2}\left(120{ }^{\circ} \mathrm{C}\right)$ por 15 minutos e caracterizadas quanto ao $\mathrm{pH}$, demanda química de oxigênio (DQO), nitrogênio total (NTK), e fósforo ( $\mathrm{P}_{-} \mathrm{PO}_{4}{ }^{-3}$ ), segundo metodologia descrita em Standard Methods for Examination of the Water and Wastewater (Apha, 2005). 


\subsection{Obtenção dos dados cinéticos}

Os experimentos foram conduzidos em biorreator operando em batelada, alimentado com 4,5 L de efluente, temperatura de 10,20 e $30^{\circ} \mathrm{C}$, ausência de luminosidade, e aeração contínua de $1 \mathrm{vvm}$. A concentração celular foi monitorada a cada 4 horas. Os dados cinéticos foram usados para a estimativa dos parâmetros: velocidade máxima específica de crescimento $\left(\mu_{\max }, \mathrm{h}^{-1}\right)$, tempo de geração $(\operatorname{tg}, \mathrm{h}) \mathrm{e}$

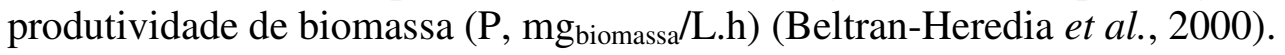

\section{Planejamento experimental}

Um planejamento experimental $3^{2}$ com duas variáveis independentes (temperatura de cultivo e concentração de inóculo) em três níveis a fim de avaliar o efeito destas variáveis sob a produtividade de biomassa microalgal.

O planejamento foi baseado em 9 experimentos em triplicata. As variáveis e os níveis estão apresentados na Tabela 1.

Tabela 1. Matriz do planejamento experimental

\begin{tabular}{lcc} 
Tratamento & \multicolumn{2}{c}{ Valores reais e codificados } \\
1 & $\mathrm{X} 1$ & $\mathrm{X} 2$ \\
2 & $-1(10)$ & $-1(100)$ \\
3 & $-1(10)$ & $0(200)$ \\
4 & $-1(10)$ & $+1(300)$ \\
5 & $0(20)$ & $-1(100)$ \\
6 & $0(20)$ & $0(200)$ \\
7 & $0(20)$ & $+1(300)$ \\
8 & $+1(30)$ & $-1(100)$ \\
9 & $+1(30)$ & $0(200)$ \\
$\mathrm{X}_{1}$ : temperatura de cultivo $\left({ }^{\circ} \mathrm{C}\right) \mathrm{X}_{2}:$ concentração de inóculo $\left(\mathrm{mg}\right.$. $\left.\mathrm{L}^{-1}\right)$.
\end{tabular}

De acordo com as resposta do planejamento experimental os efeitos de cada variável, foram calculados e as interações entre eles determinadas. As superfícies de respostas foram obtidas, através da definição de modelos empíricos, segundo a Equação 1.

$$
Y=\beta_{0}+\beta_{1} X_{1}+\beta_{2} X_{2}+\beta_{3} X_{3}+\beta_{11} X_{1}^{2}+\beta_{22} X_{2}^{2}+\beta_{33} X_{3}^{2}+\beta_{12} X_{1} X_{2}+\beta_{13} X_{1} X_{3}+\beta_{23} X_{2} X_{3}
$$

Onde: $X_{1}, X_{2}$ e $X_{3}$ são os níveis codificados das variáveis independentes; $\beta$ é o coeficiente de regressão ( $\beta_{0}$ : intercepção; $\beta_{1}, \beta_{2}, \beta_{3}$ : linear; $\beta_{12}, \beta_{13}, \beta_{23}$ : interação e $\beta_{11}$, $\beta_{22}, \beta_{33}$ : coeficientes quadráticos. 


\section{RESULTADOS E DISCUSSÃO}

O comportamento cinético para a Aphanothece microscopica Nägeli, cultivada no efluente de laticínio a diferentes temperaturas e concentrações de inóculo, podem ser avaliados nas figuras 1,2 e 3 .

Segundo Pelczar et al. (2007) a curva de crescimento de um sistema fechado de cultivo, é definida por três fases, correspondentes a um período inicial (fase lag), na qual não há um aumento da concentração celular, seguido por um crescimento exponencial (fase log), onde a maior taxa de crescimento celular é registrada, até ao momento, que ocorre o esgotamento do meio de cultura e a biomassa aumenta apenas gradativamente ou permanece constante (fase estacionária). Na fase estacionária, ocorre a lise celular, liberando novos substratos, que serve de fonte de energia, para manter o crescimento lento dos micro-organismos que sobrevivem. O processo termina, quando o número de células viáveis diminui em função da mortalidade, cuja taxa aumenta progressivamente, decrescendo paralelamente a produção de biomassa, devido a autólise sobre ação de enzimas da própria célula. Observa-se pela análise das figuras 1 , 2 e 3, nitidamente, o efeito da temperatura e da concentração do inóculo na definição das fases de crescimentos, com máximos de duração da fase logarítmica de 8 horas, com registro da fase de declínio de uma forma geral após um tempo de residência de 20 horas.

Este rápido crescimento é típico de cianobactérias cultivadas no efluente de indústrias de alimentos, o que demonstra a capacidade destes micro-organismos em removerem e assimilarem heterotroficamente compostos orgânicos e inorgânicos de efluente (Guerrero et al., 1999; Bastos et al., 2004; Queiroz et al., 2004; Hornes \& Queiroz, 2005; Queiroz et al., 2007). O comportamento descrito pelas curvas de crescimento indicam que o tempo de detenção celular de 24 horas foi suficiente para definir o crescimento da cianobactéria em estudo, quando cultivado no efluente da indústria de laticínio. 


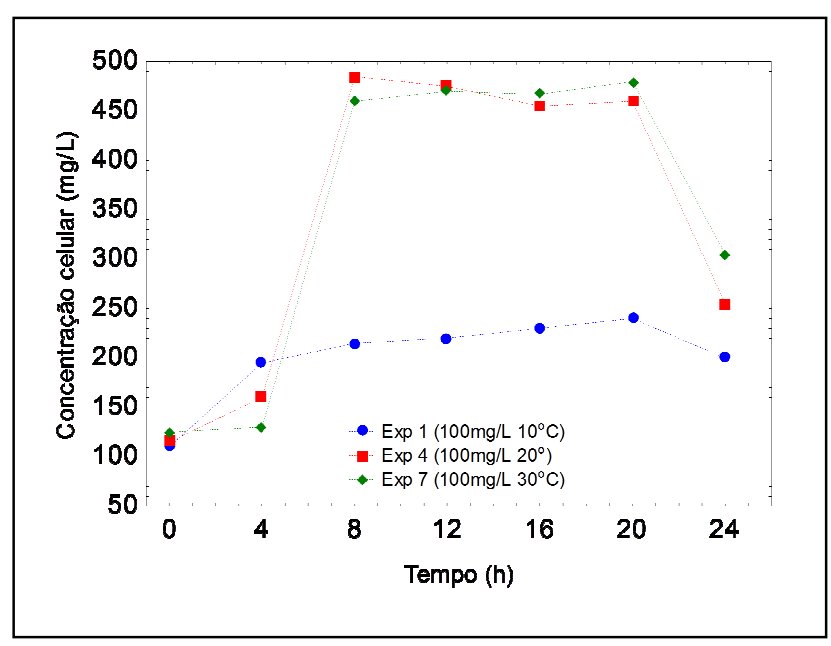

Figura 1Curvas de crescimento para culturas de Aphanothece microscopica Nägeli a partir de $100 \mathrm{mg} . \mathrm{L}^{-1}$ de inóculo nas temperaturas de cultivos 10,20 e $30^{\circ} \mathrm{C}$.

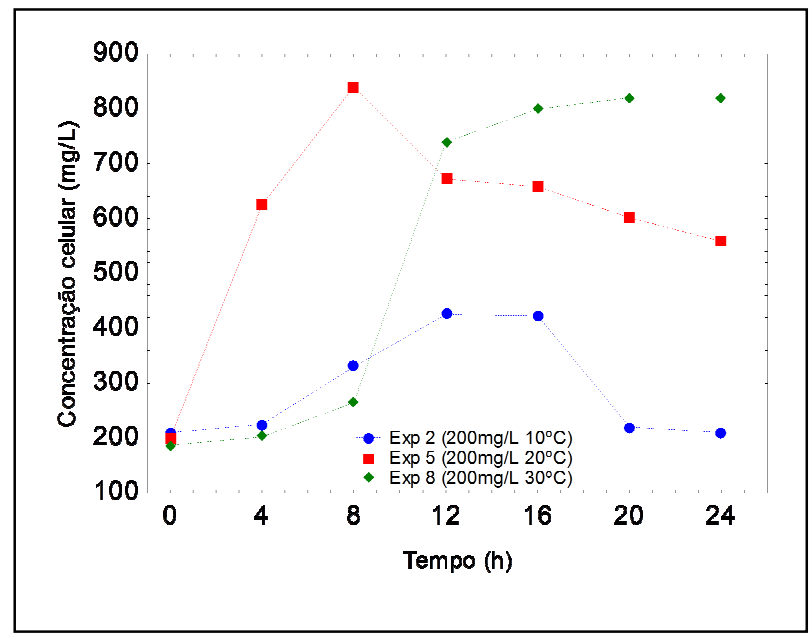

Figura 2 Curvas de crescimento para culturas de Aphanothece microscopica Nägeli a partir de $200 \mathrm{mg} . \mathrm{L}^{-1}$ de inóculo nas temperaturas de cultivos 10,20 e $30^{\circ} \mathrm{C}$.

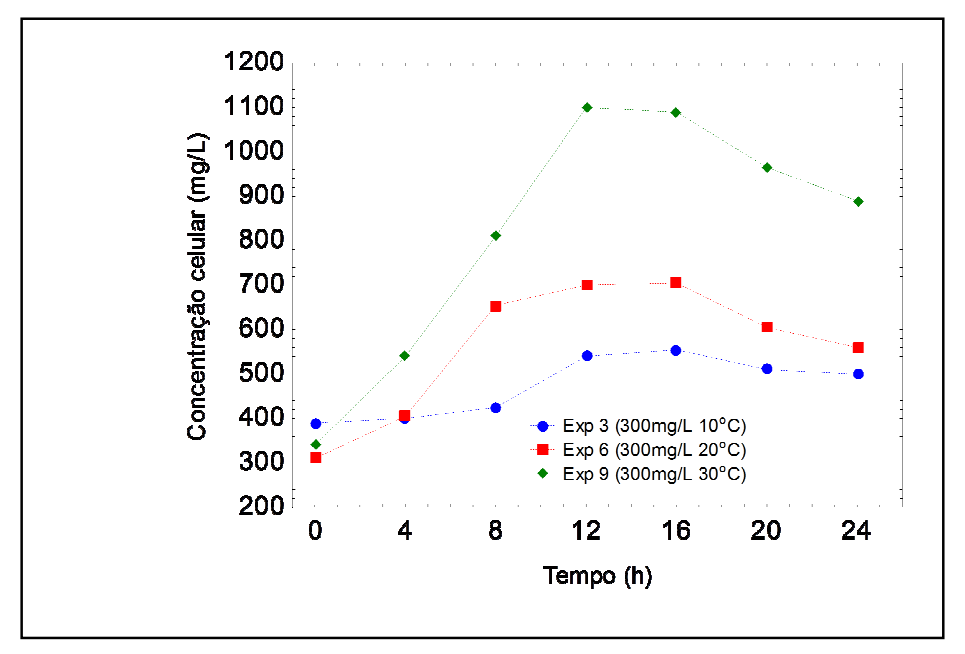

Figura 3 Curvas de crescimento para culturas de Aphanothece microscopica Nägeli a partir de 300 $\mathrm{mg} . \mathrm{L}^{-1}$ de inóculo nas temperaturas de cultivos 10 , 20 e $30^{\circ} \mathrm{C}$.

A avaliação da cinética de crescimento da Aphanothece microscopica Nägeli cultivada no efluente da indústria de laticínios pode ser avaliada na tabela 2. 
Tabela 2. Parâmetros cinéticos de crescimento

\begin{tabular}{|c|c|c|c|c|c|c|c|c|c|}
\hline \multirow{2}{*}{ Parâmetros } & \multicolumn{9}{|c|}{ Experimentos } \\
\hline & 1 & 2 & 3 & 4 & 5 & 6 & 7 & 8 & 9 \\
\hline $\mathrm{X}_{\max }$ & 240 & 335 & 540 & 485 & 841 & 850 & 460 & 1045 & 1100 \\
\hline TR & 12 & 12 & 12 & 8 & 4 & 8 & 8 & 6 & 12 \\
\hline$\mu_{\max }$ & 0,0186 & 0,0405 & 0,0375 & 0,0799 & 0,36 & 0,1261 & 0,163 & 0,25 & 0,0982 \\
\hline $\operatorname{tg}(\mathrm{h})$ & 37,27 & 17,11 & 18,48 & 3,86 & 1,92 & 5,50 & 4,25 & 2,77 & 7,06 \\
\hline $\begin{array}{c}\mathrm{Y}_{\mathrm{X} / \mathrm{S}} \\
\left(\mathrm{mg}_{\text {biomassa }} / \mathrm{mg}_{\mathrm{DQO}}\right)\end{array}$ & 0,67 & 0,48 & 0,88 & 1,31 & 0,89 & 0,95 & 0,98 & 0,56 & 1,30 \\
\hline $\begin{array}{c}\mathrm{Y}_{\mathrm{X} / \mathrm{S}} \\
\left(\mathrm{mg}_{\text {biomassa }} / \mathrm{mg}_{\mathrm{NTK}}\right)\end{array}$ & 21,21 & 13,63 & 11,26 & 8,43 & 101,7 & 8,12 & 25,73 & 44,52 & 29,25 \\
\hline $\mathrm{Px}$ & 4,16 & 10,41 & 11,67 & 46,25 & 160,2 & 67,50 & 41,9 & 136,7 & 63,33 \\
\hline $\begin{array}{l}\text { Remoção de } \\
\text { fósforo }(\%)\end{array}$ & 4,4 & 70,2 & 65,2 & 43,9 & 95,5 & 50,7 & 77,8 & 7,31 & 84,4 \\
\hline
\end{tabular}

$\mathrm{X}_{\max }$ : concentração máxima de biomassa $\left(\mathrm{mg} . \mathrm{L}^{-1}\right)$; TR: tempo de residência celular (h); $\mu_{\operatorname{máx}}$ : velocidade específica de crescimento máxima $\left(h^{-1}\right)$; tg: tempo de geração $(h)$; $Y_{X / S}$ : fator de conversão de substrato em célula; $\mathrm{P}_{\mathrm{X}}$ : produtividade de biomassa $\left(\mathrm{mg} \cdot \mathrm{L}^{-1} \mathrm{~h}^{-1}\right)$; Produção de carboidratos extracelulares (mg. $\left.\mathrm{L}^{-1}\right)$. Experimentos: $1\left(10^{\circ} \mathrm{C}, 100 \mathrm{mg} \cdot \mathrm{L}^{-1}\right), 2\left(10^{\circ} \mathrm{C}, 200 \mathrm{mg} . \mathrm{L}^{-1}\right)$, $3\left(10^{\circ} \mathrm{C}, 300 \mathrm{mg} \cdot \mathrm{L}^{-1}\right), 4\left(20^{\circ} \mathrm{C}, 100 \mathrm{mg} . \mathrm{L}^{-1}\right), 5\left(20^{\circ} \mathrm{C}, 200 \mathrm{mg} . \mathrm{L}^{-1}\right), 6\left(20^{\circ} \mathrm{C}, 300 \mathrm{mg} . \mathrm{L}^{-1}\right), 7\left(30^{\circ} \mathrm{C}\right.$, $\left.100 \mathrm{mg} . \mathrm{L}^{-1}\right), 8\left(30^{\circ} \mathrm{C}, 200 \mathrm{mg} . \mathrm{L}^{-1}\right)$ e $9\left(30^{\circ} \mathrm{C}, 300 \mathrm{mg} \cdot \mathrm{L}^{-1}\right)$.

Os dados cinéticos obtidos, fazem desta água residuária um importante potencial de meio de cultura a ser utilizado para a produção de biomassa e compostos celulares, a julgar pelas concentrações celulares registradas, principalmente para o experimentos 8 (200 mg.L. $\mathrm{L}^{-1}$ de inóculo a $\left.20^{\circ} \mathrm{C}\right)$, em curto tempo de geração $(2,77 \mathrm{~h}$ ), com importante remoção de fósforo $(95,5 \%)$ em um tempo de residência de apenas 24 horas. Estes valores são substancialmente superiores se comparados as águas residuárias do processamento do pescado e parboilização do arroz (Hornes et al., 2010; Queiroz et al., 2007), o que evidencia a potencialidade do uso de resíduos agroindustriais para suportar a produção de biomassa microalgal.

Ainda analisando a tabela 2, pode-se verificar que as mais concentrações de biomassa, correspondem as maiores concentrações de inóculo e temperatura de cultivo, atingindo valores de até $1045 \mathrm{mg} . \mathrm{L}^{-1}$ e $1100 \mathrm{mg} . \mathrm{L}^{-1}$ nos cultivos realizados sob as condições dos experimentos $8\left(200 \mathrm{mg} . \mathrm{L}^{-1}\right.$ e $\left.30^{\circ} \mathrm{C}\right)$ e experimentos $9\left(300 \mathrm{mg} . \mathrm{L}^{-1} \mathrm{e}\right.$ $\left.30^{\circ} \mathrm{C}\right)$, respectivamente. No entanto, no experimento $5\left(200 \mathrm{mg} \cdot \mathrm{L}^{-1} 20^{\circ} \mathrm{C}\right)$, as maiores velocidades especifica de crescimento $\left(0,36 \mathrm{~h}^{-1}\right)$, e menores tempo de geração $(1,92 \mathrm{~h}) \mathrm{e}$ maior consumo de substratos, evidenciando o efeito da temperatura da reação biológica na conversão dos poluentes em biomassa. Os experimentos a temperatura de $30^{\circ} \mathrm{C}$ e 200 $\mathrm{mg} . \mathrm{L}^{-1}$ apresentaram velocidade máxima especifica de crescimento de $0,25 \mathrm{~h}^{-1}$ sendo este valor substancialmente superior ao obtido por Hornes \& Queiroz (2008), para o efluente do processamento do pescado e Queiroz et al. (2007), para o efluente da parboilização do arroz que foram de $0,04 \mathrm{~h}^{-1}$ e $0,11 \mathrm{~h}^{1}$, respectivamente. 
No que se refere aos experimentos conduzidos à temperatura de $10^{\circ} \mathrm{C}$ com inóculo $100 \mathrm{mg} . \mathrm{L}^{-1}, 200 \mathrm{mg} . \mathrm{L}^{-1}$ e $300 \mathrm{mg} . \mathrm{L}^{-1}$ verifica-se os menores valores para velocidade especifica de crescimento $\left(0,0186 \mathrm{~h}^{-1}, 0,0405 \mathrm{~h}^{-1}\right.$ e $\left.0,0375 \mathrm{~h}^{-1}\right)$ e maiores tempos de geração $(37,27 \mathrm{~h}, 17,11 \mathrm{~h}$ e $18,48 \mathrm{~h})$, mostrando que a redução da temperatura afetou diretamente o crescimento celular.

Os resultados das variáveis cinéticas tabela 2 ainda indicam, que independente da temperatura nos cultivos com concentração inicial de inóculo de $200 \mathrm{mg} . \mathrm{L}^{-1}$ apresentou os melhores resultados, com tempos de geração baixos e velocidades especificas de crescimento elevadas, seguidos dos cultivos com inóculo de $300 \mathrm{mg} . \mathrm{L}^{-1} \mathrm{e}$ $100 \mathrm{mg} . \mathrm{L}^{-1}$, ficando demonstrado que tanto a concentração de inóculo como a temperatura de cultivo influenciaram no crescimento do micro-organismo.

A análise da figura 4 evidencia, que não só a temperatura exerce influência no crescimento celular, considerando que tanto este fator como a concentração de inóculo possui efeito significativo na produtividade de biomassa, assim como a interação dos fatores $(\mathrm{p}=0,05)$. Ficou demonstrado ainda um efeito maior da concentração de inóculo sob a resposta produtividade de biomassa quando comparado com o efeito da temperatura de cultivo.

O efeito da temperatura no crescimento de cianobactérias, tem sido estudado por outros autores, que reportam melhor crescimento em temperaturas de $30^{\circ} \mathrm{C}$ a $35^{\circ} \mathrm{C}$, tais como Martínez et al. (2000) e Mathiensen et al. (1999), quando cultivada no efluente da parboilização do arroz, sendo registrado maior crescimento celular a $35^{\circ} \mathrm{C}$. O efeito da temperatura é corroborada com o trabalho de Matthiensen et al. (1999), que estudaram ao longo de doze meses florações de cianobactérias na região estuarina da Lagoa dos Patos e verificando que o valor máximo alcançado foi de $1,3.10^{6}$ células. $L^{-1}$ em dezembro e o mínimo de $1,5.10^{5}$ células. $\mathrm{L}^{-1}$ em agosto, demonstrando o efeito da temperatura no crescimento do micro-organismo.

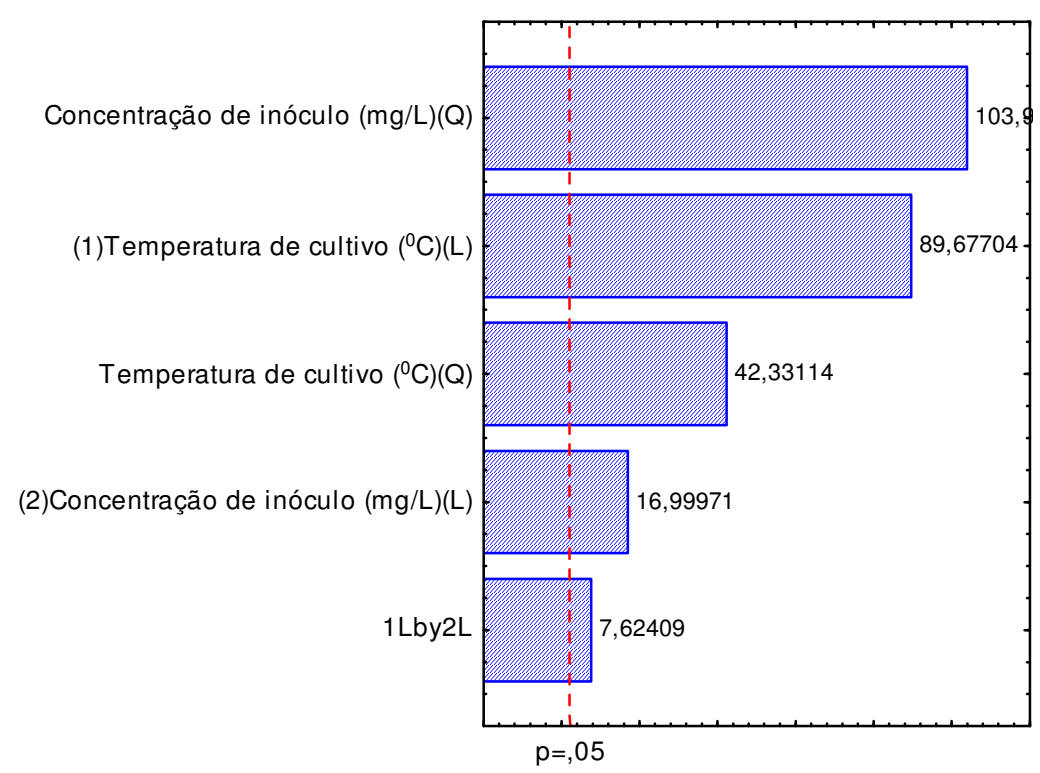

Figura 4. Efeito das variáveis temperatura de cultivo (1) e concentração de inóculo (2) sobre a produtividade de biomasa de Aphanothece microscopica Nägeli. (1), (2) efeitos principais; (1)(2) efeitos de interação dos dois fatores. 


\section{CONCLUSÃO}

Em termos cinéticos, a temperatura da reação biológica e a concentração de inóculo afetou o crescimento celular, bem como a remoção de fósforo.

Os experimentos nas condições de $200 \mathrm{mg} . \mathrm{L}^{-1}$ de inóculo e $20^{\circ} \mathrm{C}$ se obteve as maiores velocidades de crescimento celular e maior remoção de fósforo.

\section{REFERÊNCIAS}

APHA -AMERICAN PUBLIC HEALTH ASSOCIATION Standard Methods for the Examination of Water and Wastewater. $20^{\circ} \mathrm{Ed}$. Washington, 2005.

BASTOS, R. G. et al. Remoção de nitrogênio e matéria orgânica do efluente da parboilização do arroz por Aphanothece microscopica Nägeli na ausência de luminosidade. Engen. Sanit. Ambient., v. 9, p. 112-116, 2004.

BELTRAN-HEREDIA, J.; TORREGROSA, J.; DOMINGUEZ, J. R.; et al. Aerobic biological treatment of black table olive washing wastewaters: effect of an ozonation stage. Process Biochem., v. 35, p. 1183-1190, 2000.

CHIMENOS, J.M.; FERNANDEZ, A.I.; HERNANDEZ, A.; HAURIE, L.; ESPIELL, F.; AYORA, C. Optimization of phosphate removal in anodizing aluminum wastewater. Water Research. vol. 40; p.137-43, 2006.

FONTENOT, Q.; BONVILLAIN, C.; KILGEN, M.; BOOPATHY, R. Effects of temperature, salinity, and carbon: nitrogen ratio on sequencing batch reactor treating shrimp aquaculture wastewater. Bioresour. Technol., v. 98, p. 1700-1703, 2007.

GOLDER, A.K.; SAMANTA, A.N.; RAY, S. Removal of phosphate from aqueous solutions using calcined metal hydroxide sludge wastewater generated from electrocoagulation. Separ. Purifi. Technol., vol. 52, p. 102-9, 2006.

GUERRERO, L.; OMIL, F.; MÉNDEZ, R.; et al.. Anaerobic hidrolysis and acidogenesis of wastewaters from food industries with high content of organic solids and protein. Water Research, v. 33, p. 3281- 3290, 1999.

HAMDANI, A.; MOUNTADAR, M.; ASSOBHEI, O. Comparative study of the efficacy of three coagulants in treating dairy factory waste water. Int. J. Dairy Technol., v. 58, p. 83-88, 2005.

HAFTING, J. T. Effect of tissue nitrogen and phosphorus quota on growth of Porphyra yezoensis blades in suspension cultures. Hydrobiologia, v. 398-399, p. 305-314, 1999.

HORNES, M.O.; QUEIROZ, M.I. Valoração do efluente da indústria processadora de pescado por incorporação de nutrientes em Aphanothece microscopica Nägeli. Tese de Doutorado em Engenharia e Ciência de Alimentos. FURG, Rio Grande, RS, 2008. $221 \mathrm{p}$.

HORNES, M.O.; QUEIROZ, M.I. Efeito da razão C/N e do inóculo na remoção de nitrogênio do efluente da indústria da pesca pela cianobactéria Aphanothece microscopica Nägeli. Vetor, 15(1): 25-32, 2005.

HORNES, M.; SILVA, A.G; MITTERER, M.L; QUEIROZ, M.I. Influência dos compostos nitrogenados na concentração de proteína da cianobactéria Aphanothece microscopica Nägeli. Ciênc. Tecnol Aliment., v. 30, p. 1-371, 2010.

IRDEMEZ, S.; DEMIRCIOGLU, N.; SEVKI, Y.; BINGUL, Z. The effects of current density and phosphate concentration on phosphate removal from wastewater by 
electrocoagulation using aluminum and iron plate electrodes. Separ. Purifi. Technol. v. 52, p. 218-23, 2006.

LEE, W.Y.; PARK, Y.; AHN, J.K.; KA, K.H.; PARK, S.Y. Factors influencing the production of endopolysaccharide and exopolysaccharide from Ganoderma applanatum. Enzyme and Microb. Technol., v. 40, p. 249-254, 2007.

LI, S.; LIA, H.; LIANGA, X.Q.; CHENA, Y.X.; WANGA, S.X.; WANGA, F.E. Phosphorus removal of rural wastewater by the paddy-rice-wetland system in Tai Lake Basin. J. Hazard. Mater., v.171 p. 301-308, 2009.

MARTÍNEZ, M. E.; SÁNCHEZ, S.; JIMÉNEZ, J. M.; YOUSFI, F. El.; MUÑOZ, L. Nitrogen and phosphorus removal from urban wastewater by the microalga Scenedesmus obliquus. Bioresour. Technol, v. 73, p. 263-272, 2000.

MATHIENSEN, A.; YUNES, J. S.; CODD, G. A. Ocorrência, distribuição e toxicidade de cianobactérias no estuário da Lagoa dos Patos, RS. Rev. Bras. Biol., v. 59, p. 361-376, 1999.

MISHRA, A.; JHA, B. Isolation and characterization of extracellular polymeric substances from micro-algae Dunaliella salina under salt stress. Bioresour. Technol, v. 100, p. 3382-3386, 2009.

PELCZAR JR., M. J.; CHAN, E. C. S.; KRIEG, N. R. Microbiologia; conceitos e aplicações. 2007. ed. São Paulo: Pearson Makron Books, V. 1, 2.

QUEIROZ, M. I. ; JACOB, E. ; ZEPKA, L. Q. ; BASTOS, R. . The kinetics of the removal of nitrogen and organic matter from parboiled rice effluent by cianobacteria in a stirred batch reactor. Bioresour. Technol, v. 98, p. 2163-2169, 2007.

QUEIROZ, M. I.; BENERI, R.; BASTOS, R.; ALMEIDA, R. Single-cell protein production by Aphanothece microscopica Nägeli in rice parboilized effluent. Food Sci. Biotechnol., v. 13, n. 1, p. 142-150, 2004.

RIPPKA, R.; DERUELLES, J.; WATERBURY, J. B.; HERDMAN, M.; STANIER, R. Y. Generic assignments strain histories and properties of pure cultures of cyanobacteria. J. General Microbiol. Great Britain. n. 111. p. 01-61, 1979.

SARKAR, B; CHAKRABARTI, P.P; VIJAYKUMAR, A.; KALE, V. Wastewater treatment in dairy industries-possibility of reuse. Desalination, v. 195, p. 1-3, 2006.

SHU, C.H.; LUNG, M.Y. Effect of $\mathrm{pH}$ on the production and molecular weight distribution of exopolysaccharide by Antrodia camphorata in batch cultures. Process Biochemistry, v. 39, p. 1-7, 2003.

\section{AGRADECIMENTOS}

Os autores agradecem a Coordenação de Aperfeiçoamento de Pessoal de Nível Superior (CAPES). 